\title{
ENTRE GOVERNOS AUTORITÁRIOS E ASPIRAÇÕES FASCISTAS NA ATUALIDADE: O CONTEXTO INTERNACIONAL AO BRASIL
}

\author{
ENTRE LOS GOBIERNOS AUTORITARIOS Y TENDENCIAS FASCISTAS EN LA \\ ACTUALIDAD: DE CONTEXTO INTERNACIONAL A BRASIL
}

\section{BETWEEN AUTHORITARIAN GOVERNMENTS AND THE CURRENT FASCISTS ASPECTS: THE INTERNATIONAL CONTEXT TO BRAZIL}

DOI: http://dx.doi.org/10.9771/gmed.v11i2.3319

\author{
Ricardo Gonçalves Severo ${ }^{1}$ \\ Rodrigo Duque Estrada ${ }^{2}$ \\ Sérgio Botton Barcellos ${ }^{3}$
}

\begin{abstract}
Resumo: Este trabalho tem como questão central compreender, como as ações de grupos liberais e conservadores no Brasil, representadas pelo atual governo do país, são influenciadas pelo processo histórico de modernização conservadora nacional e a recente articulação internacional da extrema direita. Para compreender como em um processo capitalista ocorrem versões autoritárias acionaremos Barrington Moore Junior (2010) e Saull (2013;2015;2018), bem como as discussões realizada por Apple (2006; 2017) e Souza (2017) para analisar a ação de grupos neoliberais, neoconservadores, a nova classe média profissional e populistas autoritários. A partir disso, analisaremos as possíveis relações entre os fascistas históricos e a extrema-direita que atuam em coalizão em diversos países no mundo.
\end{abstract}

Palavras-chaves: extrema-direita; fascismo; modernização conservadora; governo brasileiro.

Resumén: Este articulo tiene como pregunta central comprender cómo las acciones de los grupos liberales y conservadores en Brasil, representados por el gobierno actual del Brasil, están influenciados por el proceso histórico de modernización conservadora nacional y la reciente articulación internacional de la extrema derecha. Para comprender cómo en un proceso capitalista se producen versiones autoritarias, recurriremos a Barrington Moore Junior (2010) y Saull (2013; 2015; 2018), así como a las discusiones mantenidas por Apple (2006; 2017) y Souza (2017) para analizar la acción de estos grupos neoliberales, neoconservadores, nuevos profesionales de clase media y populistas autoritarios. A partir de esto, analizaremos las posibles relaciones entre los fascistas históricos y la extrema derecha que actúan en coalición en varios países del mundo.

Palabras clave: extrema derecha; fascismo modernización conservadora; Gobierno brasileño.

Abstract: This paper has as its central question to understand how the actions of liberal and conservative groups in Brazil, represented by the current government of the Brazil, are influenced by the historical process of national conservative modernization and the articulation of the extreme right. To understand how in a capitalist process occur an authoritarian versions we will turn on Barrington Moore Junior (2010) and Saull (2013; 2015; 2018), as well as the discussions held by Apple (2006; 2017) and Souza (2017) to analyze the action of neoliberal groups, neoconservatives, new professional middle class and authoritarian populists. From this, we will analyze the possible relations between the historical fascists and the far right that act in coalition in several countries in the world.

Keywords: far right; fascism; conservative modernization; Brazilian government.

\section{Introdução}


A eleição de um representante da extrema-direita para a Presidência da República no Brasil é resultado de cinco anos de campanha a partir de uma aliança de setores liberal-conservadores e surge em um contexto de novas formas de governo com o questionamento das instituições políticas e de Estado em vários países no mundo. A jornada política do novo Presidente eleito do Brasil é marcada por uma série de pronunciamentos considerados polêmicos em vários aspectos e amplamente divulgados pelas mídias tradicionais, por mídias que se denominam alternativos e pelos sites de redes sociais tanto do campo da direita, quanto da esquerda.

Sob essa perspectiva, a questão central proposta neste trabalho é: Como as ações de grupos liberais e conservadores, representadas pelo atual governo do Brasil, são influenciadas pelo processo histórico de modernização conservadora nacional e a recente articulação internacional da extrema direita?

Para compreender a modernização conservadora iremos trabalhar por meio da acepção de Barrington Moore Junior sobre como esse conceito auxilia a explicar como o processo capitalista desenvolve uma versão autoritária. Isto é, o que nos instiga é compreender como a modernização conservadora auxilia a explicar processos autoritários que excluem a participação das massas da população de modo geral e é conduzido por determinadas elites.

A problematização teórica sobre a questão da extrema-direita no Brasil vai partir do conceito da modernização conservadora para compreender o cenário atual, mas cabe contextualizar historicamente as relações de classe e os aspectos nacionais em relação aos internacionais. Em relação ao caso brasileiro cabe analisar como essas elites atuam e como está em curso processos autoritários dirigido por um governo de extrema-direita ou "nova direita”. Para essa análise vamos acionar a discussão realizada por Michael Apple, também com aporte em outros autores, a partir de quatro grupos: neoliberais, neoconservadores, nova classe média profissional e populistas autoritários.

Metodologicamente, a discussão se apoiará nas ações políticas do atual governo do Brasil e como historicamente esse processo está se configurando em inter-relação com grupos de extrema-direita internacionalmente, em especial, na última década. Ou seja, com base em notícias e ações de governo publicizadas diariamente, a análise será fundamentada nos possíveis significados, aspirações e crenças imersas em um conjunto de relações dos grupos políticos.

Desse modo, há relações que são fundamentais para a compreensão das relações entre estes atores no Brasil que identificamos como neoconservadores e populistas autoritários a partir, por exemplo, na aliança liberal-conservadora que elege o presidente Jair Bolsonaro, Movimento Brasil Livre (MBL), Projeto Escola Sem Partido e no Congresso Nacional as bancadas evangélica na figura de setores neopentecostais, da bancada ruralista e da bancada da bala.

\section{Modernização conservadora e o fascismo: alguns aspectos conceituais}

Os principais traços a personalidade autoritária e que auxiliam a identificar formas de atuação protofascista podem ser identificados na pesquisa realizada por Adorno e sua equipe nos anos 1940 nos Estados Unidos. Mesmo com a distância histórica é possível visualizar, atualmente, a existência de tais 
traços, como: a) Tradicionalismo $0^{4}$, que se expressa numa adesão acrítica aos valores dominantes do status quo, senão com desejo de volta a um passado imaginado; b) Submissão a uma figura autoritária, a qual passa a representar os valores do grupo de referência; c) Agressividade exacerbada dirigida contra grupos identificados como inimigos, reais ou imaginários; d) Incapacidade de subjetivação, ou seja, impossibilidade de produzir relações lógicas com quaisquer elementos que fujam à observação imediata; e) Visão de mundo estereotipada e supersticiosa, que produz o entendimento social com base em categorias rígidas; f) Preocupaşão exacerbada com poder, expressa numa preocupação de demonstrar força, masculinidade e "valentia"; g) Visão cínica e destrutiva do mundo com uma narrativa e atuação de hostilidade generalizada; h) Projetividade, que expressa uma percepção de perigos contínuos à existência dos grupos de referência e que leva à tensão emocional manifesta em raiva e, por fim ; i) Preocupação continuada com o sexo, percebido não como uma condição, mas como ação, levando a situações de recalque dos grupos que aderem aos valores protofascista (com base em ADORNO, 1950, p. 228).

Tais traços são próprios de um dos grupos que fazem parte de um projeto de modernização conservadora, e conforme Michael Apple é constituído pelos neoliberais, os neoconservadores, os populistas autoritários e a nova classe média profissional (2006; 2013). Para o autor, os neoliberais são o grupo mais forte dentro desta aliança, propondo um Estado fraco no que diz respeito ao investimento e recursos públicos à população, mas com força o suficiente para resgatar grandes empresas em momentos de crise cíclica do capitalismo, tal qual ocorreu em 2008 na crise norte-americana ${ }^{5}$. A nova classe média profissional trata de uma fração da classe média que, através de um capital cultural adquirido através da formação profissional educacional, passa a desempenhar um papel de administração no Estado e no mercado.

Os neoconservadores são um grupo guiado por valores tradicionais, propondo a presença de um Estado forte, especialmente no que se refere a aspectos relacionados ao monopólio da violência, assim como preocupação e vigilância com o que compreendem com valores familiares, tentando implementar uma política moralista ao conjunto da população. Os populistas autoritários podem ser melhor representados nos Estados Unidos com a moralidade Cristã e a nova direita, sendo uma expressão mais exacerbada de valores neoconservadores. No Brasil, em nossa interpretação, ambos grupos são, em muitas circunstâncias, indistintos, sendo Bolsonaro um exemplo claro disso, pois o mesmo é conservador e neopentecostal.

Consideramos que esses grupos estão à frente do desenvolvimento da modernização conservadora não só nos Estados Unidos, mas com diferentes arranjos nacionais e formas de tensionamento entre si. Estes grupos se complementam e a partir do conceito de modernização conservadora contemporânea dos Estados Unidos, pode nos ajudar a compreender o processo atual no Brasil em que existe uma continuidade do processo de modernização conservadora de um modelo que sempre esteve sob tutela de uma classe latifundiária e de uma elite que é atrelada interesses internacionais ${ }^{6}$ (MOORE Jr., 2010).

Ainda sobre as classes médias, conforme Souza (2017), é possível identificar diferenciação entre estratos socioeconômicos no Brasil com base em diferenciais econômicos e culturais sendo a Ralé, ou subproletariado como um grupo populacional relativo aos que estão excluídos das possibilidades de acesso a níveis educacionais em razão inclusive pela exclusão realizada da classe média que utiliza-se deste monopólio 
para se manter em uma situação mesmo que de ao de proximidade de estratos superiores se vendo como elite.

\section{Da extrema-direita global ao governo Bolsonaro no Brasil}

Ressaltada a relevância do contexto internacional no processo em análise, faz-se necessário compreender primeiramente a conjuntura doméstica recente. A atual ascensão da extrema-direita ao poder possui raízes históricas mais profundas em processos relacionados a resíduos autoritários de políticas excepcionais da época da ditadura civil-militar (1964-1985) e mesmo em períodos anteriores (KAYSEL, 2015), bem como da reorganização, desde a década de 1980, de um novo modus operandi de aparatos hegemônicos privados constituídos por segmentos liberais-conservadores da burguesia brasileira (CASIMIRO, 2018). No entanto, o panorama geral desse período de crise de representação da Nova República associa-se ao rescaldo das manifestações de Junho de 2013; ao escândalo de corrupção exposto pela operação Lava-Jato, um projeto de poder que implicou num conluio entre agentes do judiciário alvejando alvos políticos deliberados, especialmente o ex-presidente Lula, e ofuscando o devido processo legal; e relacionado a este, o golpe parlamentar (impeachment) da ex-presidente Dilma Roussef, em 2016, em que o judiciário associou-se com a grande mídia liberal-conservadora mirando um lanfare contra o Partido dos Trabalhadores (PT) ao vazar seletivamente material sob investigação aos meios de comunicação (SOUZA, 2017;). Ao lado da fragilidade do campo da esquerda em organizar-se como um bloco de resistência, tais processos contribuíram para a criação de um pânico moral no qual a corrupção do Estado passou a equacionar-se ao PT em geral e ao ex-presidente Lula em específico.

A prisão de Lula desde abril de 2018, ao lado da tentativa de assassinar o então candidato Jair Bolsonaro durante uma campanha em setembro daquele ano, tornou-se no pano de fundo para o sucesso eleitoral da coalizão de extrema-direita agora empoderada no Brasil sob o Partido Social Liberal (PSL). Esta coalizão pode ser entendida como uma rede informal de organizações e indivíduos de direita e extremadireita, combinando: alinhamentos parlamentares entre representantes das bancada evangélica, do agrobusiness e do complexo da indústria de armas; intelectuais ultraconservadores, tais como Olavo de Carvalho, cujo prestígio o permitiu fazer indicações para assumir ministérios no governo e arregimentar uma massa de seguidores fanatizados; organizações civis ultraliberais tais como o Instituto Millenium, o Movimento Brasil Livre e o Instituto Mises Brasil, todos proximamente ligados a think tanks internacionais como a Atlas Network; dentre outros conhecidos agentes de Estado, investidores, oligopólios midiáticos, celebridades populares e até youtubers (CRUZ; KAYSEL; KODAS, 2015).

Ainda que Bolsonaro não seja propriamente um outsider da política nacional, tendo sido parlamentar por quase 30 anos, sua campanha foi capaz de articular a imagem de um líder antiestablishment combatendo privilégios das elites e corrupção, uma realidade que grupos e intelectuais de extrema-direita atribuem ao "marxismo cultural" e a defensores dos "Direitos Humanos" no país. Em seu discurso inaugural, Bolsonaro afirmou que seu governo lutaria pela libertação da nação da "ideologia de gênero", do “politicamente correto" e do “socialismo”. Débora Messenberg (2019, p. 36-37) aponta que a atual visão de 
mundo da direita brasileira abarca a consolidação de políticos autoritários baseados no antipetismo, no conservadorismo moral e em princípios neoliberais, sem que haja contradição em relação à presença do Estado ${ }^{7}$.

Em relação à ordem internacional, após a crise de 2008, foi gerada e intensificada uma radicalização de políticas neoliberais, afetando as relações Estado-sociedade ao redor do mundo. Uma de suas características mais penetrantes tem sido a reemergência de movimentos e partidos políticos de extrema-direita desafiando instituições e valores liberais-democráticos tradicionais, especialmente na Europa, com o fenômeno do "Brexit", e nos Estados Unidos, com o governo de Donald Trump; mas também no terceiro mundo, a exemplo dos governos de Bolsonaro no Brasil, Rodrigo Duterte nas Filipinas, Benjamin Netanyahu em Israel e Recep Tayyip Erdogan na Turquia. Esta conjuntura foi caracterizada como um "momento populista" da extrema-direita (MOUFFE 2018; HADIZ; CHRISSOGELOS, 2017), que articula uma política de confronto nativista e etnocêntrica tanto contra elites do establishment quanto à agenda de Direitos Humanos - especialmente em torno da questão da imigração e do multiculturalismo -, bem como avança uma plataforma reacionária baseada em uma economia política racializada (SAULL, 2018).

O que chama à atenção de analistas nesse fenômeno é o sucesso da extrema-direita em capturar oportunidades políticas e construir frames de ação coletiva - organizando-se, efetivamente, como um movimento social (GATTINARA; PIRRO, 2018); e expandindo suas ações através de vínculos transnacionais e cooperação internacional entre organizações partidárias e movimentos, envolvendo "compartilhamento de informações, repertórios de confronto, discursos, ideologia, aprendizagem e difusão de normas" (STENGEL; MACDONALD; NABERS, 2019, p. 8; cf. CAIANI, 2018). Observa-se o renascimento de um "internacionalismo reacionário" que, apesar de ser composto por movimentos nacionalistas, se une para combater inimigos em comum a fim de refundar as bases sociais da "nação": ordem, família, propriedade, patriarcado, etc. Assim, é comum que lideranças da extrema-direita, como Steve Bannon, ex-estrategista de Trump e fundador do "The Movement", Mateo Salvini, Ministro do Interior da Itália, e Viktor Orbán, presidente da Hungria, participem de confraternizações e campanhas políticas de lideranças semelhantes ao redor do mundo para arregimentar e coordenar alianças. O governo de extremadireita de Bolsonaro insere-se nesta mesma lógica.

Essa tendência prenuncia o "internacional” como domínio constitutivo da atual onda da política de extrema-direita, como explorado na recente literatura da Sociologia Histórica, que utiliza a perspectiva do longue dureé a fim de compreender sua evolução e processos sociais (SAULL, 2013 e 2018; SAULL et al., 2015). A principal ideia desta literatura é que a extrema-direita não representa um fenômeno social autônomo ou desviante, mas está profundamente implicada no desenvolvimento estrutural do capitalismo: a extrema-direita está "inextricavelmente ligada às diversas maneiras pelas quais o capitalismo reconstitui o significado, o terreno e a dinâmica do político" (SAULL et al., 2015, p. 6). Assim, a política de inimizade reacionária e via regra violenta associada à extrema-direita, que reifica uma ordem social hierárquica, patriarcal e racializada não deve ser vista como uma falha da política (neo)liberal, mas, pelo contrário, um elemento constitutivo e ambivalente de suas operações políticas em tempos de crise (SAULL, 2018). 
Períodos de aguda crise econômica são historicamente favoráveis à ascensão da extrema-direita, pois a elite dominante, temerosa em perder sua posição socioeconômica, encontra em populistas radicais de direita uma fonte de segurança para o restabelecimento da ordem capitalista dominante. Um estudo analisando as consequências políticas de cerca de 100 crises financeiras entre 1840-2014 em 20 democracias aponta que 30\% da média dos votos em eleições pós-crise vão para a extrema-direita, sendo que a extremaesquerda permanece com a mesma composição (FUNKE; SCHULARICK; TREBESCH, 2015). Ao mesmo tempo, a extrema-direita também age propositivamente no cenário internacional, visando alterar padrões de comportamento, revisando instituições e regimes internacionais e intensificando conflitos sociais. É assim que, por meio de solidariedade e cooperação com outros movimentos e partidos, a política da extremadireita tem se transformado num campo ambíguo de contestação e endosso da economia política neoliberal hegemônica (WORTH, 2015).

Para a análise da extrema-direita brasileira contemporânea, limitamos o escopo analítico à segunda forma de agência, compreendendo a extrema-direita como uma patologia incorporada da ordem neoliberal, que "necessitou de uma estratégia política populista associada a correntes da direita e extrema-direita a fim de assegurar sua hegemonia política sob a forma de governança” (SAULL, 2018, p. 7). Essa perspectiva de um "neoliberalismo autoritário" (JUEGO, 2018) acompanha também a trajetória histórica da política de extrema-direita latino-americana, epitomizada no casamento da vertente hayekiana do neoliberalismo com o governo autoritário de Pinochet no Chile contra as reformas sociais de Salvador Allende.

$\mathrm{Na}$ América Latina, essa tendência vinculando neoliberalismo com a extrema-direita tem sido recentemente encapsulada no chamado ciclo do "voto com raiva" (MALAMUD; NÚÑEZ, 2018), encabeçando os assim-chamados políticos outsiders que conseguiram canalizar, convincentemente, o descontentamento popular à política partidária tradicional e mobilizar jargões e um imaginário de extremadireita em suas plataformas políticas populistas. Isto, ao lado dos "golpes brandos" no continente (Honduras em 2009, Paraguai em 2012 e Brasil em 2016), pôs um fim à “onda rosa” de quase duas décadas de governos latino-americanos de centro-esquerda engajados em políticas econômicas redistributivas e agendas sociais progressistas, ainda que não independentemente do quadro neoliberal, como sugere o caso brasileiro.

Apesar de crescentemente evidente, a literatura não tem dado suficiente atenção às conexões e constituições internacionais da política de extrema-direita brasileira contemporânea. Analistas têm caracterizado a extrema-direita brasileira em termos de três vertentes ideológicas interligadas: : 1) libertarianismo radicalizado; 2) fundamentalismo religioso; e 3) a reciclagem do velho anti-comunismo (MIGUEL, 2018; ver também ALMEIDA, 2018; CARAPAÑA, 2018). Todos estes estabeleceram-se sob redes específicas de articulação políticas e de liderança, bem como encontrado caminhos cruzados em anos recentes. É por isso que a extrema-direita brasileira tem fixado-se no internacional "como o 'espectro' e fonte de medo, hostilidade $e$ oportunidade" (SAULL et al., 2015, p. 13).

Exemplo disso são: a articulação internacional do clã Bolsonaro com Steve Bannon, um dos proprietários da controversa ex-empresa Cambrigde Analytica ${ }^{8}$, especialmente através do emprego de mídias sociais, tais como o Whatsapp e Facebook ${ }^{9}$; a possível nomeação de Eduardo Bolsonaro para a embaixada dos Estados Unidos, compreendido como um dos seus principais articuladores na América Latina de grupos 
de extrema-direita ${ }^{10}$; a articulação transnacional de uma perspectiva econômica neoliberal e conservador associando os assim-chamados "Chicago boys" a think tanks globais (ALMEIDA, 2018; ROCHA, 2015); e a articulação de lideranças evangélicas, incluindo a família Bolsonaro, com a extrema-direita israelense, que nos últimos anos tem aprofundado os laços com partidos de extrema-direita ao redor do mundo em busca de solidariedade à causa sionista. A condecoração de Benjamin Netanyahu com a Ordem do Cruzeiro no primeiro mês do mandato de Bolsonaro, as tratativas de transferência da embaixada brasileira de Tel-Aviv para Jerusalém e a abstenção do Brasil em votação na Comissão de Direitos Humanos da ONU contra Israel, quebrando uma tradição histórica de apoio à autodeterminação palestina, constituem expressões desse processo de alinhamento com a extrema-direita sionista.

\section{Considerações finais}

Devemos considerar que as articulações destes grupos de extrema-direita estão tendo êxitos recentes em processos eleitorais democráticos em vários países e vem gerando reflexões no sentido de entender como está ocorrendo esse plano internacional que pretende, inclusive no Brasil, pulverizar uma ideologia fundamentalista embasada em teorias conspiracionistas como terraplanismo, negacionismo climático, movimento antivacina e Marxismo cultural.

Entre esses grupos que se situam a extrema direita ou a uma direita liberal e que disputam o interior do Estado conforme (Apple, 2006; 2017) no Brasil pode-se analisar que atualmente de certa forma a ideia da oposição de um governo que ofereça soluções fáceis para problemas complexos da sociedade no século XXI se dão de certa forma no governo que resolve as coisas com soluções simples, em oposição ao "excesso de diálogo" de uma democracia, pois é necessária ações de demonstração de autoridade.

Isto é, a partir deste conjunto de exemplos baseados em evidências, consideramos que a eleição de governos de extrema-direita com feições autocráticas e autoritárias, dentre elas a eleição de Bolsonaro, são apenas a "ponta do iceberg" de uma série de relações sociais entre diferentes atores de classes sociais distintas que perpassam a questão do "nós e os outros"/ "eu e os outros"e abrange um processo muito complexo no qual está em disputa os rumos sociais e planetários ao longo do século XXI.

\section{Referências:}

ADORNO, Theodor; FRENKEL-BRUNSWIK, E.; LEVINSON, D. J e SANFORD, R. N. The Authoritarian Personality. New York: Harper, 1950.

ALMEIDA, S. L. Neoconservadorismo e liberalismo. In E. S. Gallego (org.), O Ódio como Política: a reinvenção das direitas no Brasil (pp. 27-33). São Paulo: Boitempo, 2018.

APPLE, Michael W. A Educação pode mudar a sociedade? Petrópolis, RJ: Vozes, 2017.

APPLE, Michael W. Educating the "Right" Way: markets, standards, god, and inequality. $2^{\mathrm{a}}$ ed. EUA, Taylor \& Francis: 2006.

CAIANI, M.. Radical right cross-national links and international cooperation. In J. Rydgren (Ed.), The Oxford handbook of the radical right (pp. 394-411). Oxford: Oxford University Press, 2018. 
CASIMIRO, Flávio. As classes dominantes e a nova direita no Brasil contemporâneo. In E. S. Gallego (org.), O Ódio como Política: a reinvenção das direitas no Brasil (pp. 41-46). São Paulo: Boitempo, 2018.

CHRYSSOGELOS, Angelos. Reaction and adaptation in the longue durée: the far-right, international politics and the state in historical perspective. In R. Saull et al. (eds.), The Longue Durée of the Far-Right: an international historical sociology (pp. 85-104). Routledge: Oxon, 2015.

CRUZ, S.; KAYSEL, A.; and CODAS, G. Direita, volver! O retorno da direita e o ciclo político brasileiro. São Paulo: FPA, 2015.

GATINARRA, P; PIRRO, A. The far right as social movement. European Societies, vol. 21, n. 4, pp. 447462, 2019.

HADIZ, V. R.; ChryCHRYSSOGELOS, A. Populism in world politics: A comparative cross-regional perspective. International Political Science Review, 38(4), 399-411, 2017.

JUEGO, Bonn. Authoritarian Neoliberalism: Its Ideological Antecedents and Policy Manifestations from Carl Schmitt's Political Economy of Governance.” Administrative Culture 19 (1), 105-136, 2018.

KAYSEL, André. Regressando ao regresso: elementos para uma genealogia das direitas brasileiras. In S. V. Cruz, A. Kaysel, and G. Codas (orgs.), Direita, volver! O retorno da direita e o ciclo politico brasileiro (pp. 49-74). São Paulo: FPA, 2015.

MALAMUD, C.; NÚÑEZ, R. The anger vote: the new (or not so new) Latin American electoral phenomenon. Real Instituto Elcano. Publicado em 20 de setembro de 2018. Disponível em: $<$ http://www.realinstitutoelcano.org/wps/portal/rielcano en/contenido?WCM GLOBAL CONTEXT =/elcano/elcano in/zonas in/latin+america/ari107-2018-malamud-nunez-anger-vote-latin-americanelectoral-phenomenon> Acesso em: 19/08/2019.

MANNHEIM, Karl. O Pensamento Conservador. In: MARTINS, José de Souza (Org.). Introdução Crítica à Sociologia Rural. São Paulo: Hucitec, 1986.

MESSENBERG, Debora. A cosmovisão da "nova" direita brasileira. IN: PINHEIRO-MACHADO, Rosana; FREIXO, Adriano de. Brasil em Transe: bolsonarismo, nova direita e desdemocratização. Rio de Janeiro: Oficina Raquel, 2019.

MOORE Jr. Barrington. As Origens Sociais da Ditadura e da Democracia. Lisboa: Edições 70, 2010. MOUFFE, Chantal. For a Left Populism. Lonres: Verso, 2018.

PIRES, Murilo José de Souza; RAMOS, Pedro. O Termo Modernização Conservadora: sua origem e utilização no Brasil. IN: Revista Econômica do Nordeste. volume 40, nº 3, julho-setembro 2009.

ROCHA, Camila. Direitas em rede: think tanks de direita na América Latina. . In S. V. Cruz, A. Kaysel, and G. Codas (orgs.), Direita, volver! O retorno da direita e o ciclo politico brasileiro (pp. 261-278). São Paulo: FPA, 2015.

SAULL, Richard. Racism and Far Right Imaginaries Within Neo-liberal Political Economy. New Political Economy, 23:5, 588-608, 2018.

. The origins and persistence of the far-right: Capital, class and pathologies of liberal politics. In R. Saull et al. (eds.), The Longue Durée of the Far-Right: an international historical sociology (pp. 21-42). Routledge: Oxon, 2015 2013. . Capitalist Development and the Rise and 'Fall' of the Far-Right. Critical Sociology, 0:0, 1-21,

SAULL, Richard et al.. The Longue Durée of the Far-Right: an international historical sociology. (Routledge: Oxon), 2015.

SOUZA, Jessé. A Elite do Atraso: Da Escravidão à Lava Jato, São Paulo: Editora Leya, 2017. 242p.

STENGEL, F.; MACDONALD, D.; NABERS, D. Introduction: Analyzing the Nexus Between Populism and International Relations. In: Frank Stengel, David MacDonald e Dirk Nabers (eds.), Populism and World Politics: Exploring Inter-and Transnational Dimensions, pp. 1-22. Cham, Suíça: Palgrave Mcmillan, 2019. 
SUÁREZ, Daniel. O Princípio Educativo da nova direita, neoliberalismo, ética e escola pública. IN: GENTILI, Pablo (org.) Pedagogia da Exclusão: crítica ao neoliberalismo em educação. $19^{a}$ ed. Petrópolis, RJ: Vozes, 2013.

WORTH, Owen. The Far-Right and neoliberalism: Willing partner or hegemonic opponent? In R. Saull et al. (eds.), The Longue Durée of the Far-Right: an international historical sociology (pp. 153-172).

Routledge: Oxon, 2015.

\section{Notas:}

1 Professor Adjunto na Área de Sociologia e Docente Permanente da Pós-Graduação em Educação da FURG. ORCID: http://orcid.org/0000-0001-8413-7159 Email: rg.severo@hotmail.com

2 Doutorando em Política na universidade de York, Inglaterra. ORCID: http://orcid.org/0000-0002-7509-6911 Email: rodpanzera@gmail.com

3 PPGEA-FURG/PPGS-UFPel. ORCID: http://orcid.org/0000-0002-6935-4398 Email: sergiobbarcellos@hotmail.com

${ }^{4}$ Característica apontada originalmente por Karl Mannheim, sendo o tradicionalismo uma "inclinação oculta" que tende a se realizar em movimento político organizado em grupos conservadores (1986)

${ }^{5}$ Cronologia da Crise (BBC News. Link: https://bbc.in/2YVmuJS).

${ }^{6}$ Foge do escopo do presente artigo, mas interessante análise sobre o emprego do conceito de modernização conservadora no Brasil pode ser encontrado no artigo de Pires e Ramos (2009).

7 Como observa Daniel Suárez (2013, p. 242), a articulação neoliberal e neoconservadora busca o "enfraquecimento do Estado em certas áreas (por exemplo, nas políticas de promoção social e educacional) e seu fortalecimento em outras (sobretudo nas vinculadas com o controle do disciplinamento social)".

8 A equipe da Cambridge Analytica esteve no Brasil durante a eleição presidencial ao mesmo tempo Eduardo Bolsonaro esteve reunido com Bannon durante o processo eleitoral nos Estados Unidos. Nesta eleição a Cambridge Analytica também prestou serviços a Trump.

${ }^{9}$ Sobre a manipulação de eleições utilizando-se de dados sobre usuários disponíveis na internet, recomenda-se o documentário Verdade Hackeada. Ainda, sobre a influência do algoritmo do Youtube para a ascensão da extrema-direita no Brasil, recomenda-se o artigo do New York Times "How youtube radicalized Brazil” (link: https://nyti.ms/2TDk1xK).

${ }^{10}$ Eduardo Bolsonaro foi o idealizador da Cúpula conservadora das Américas de acordo com o jornal The Intercept em matéria recentemente divulgada. Essa cúpula teve como objetivo traçar estratégias para o combate da esquerda no continente latinoamericano o evento foi organizado pela Fundação Indigo que é financiada pelo PSL. Ler mais no link: https://bit.ly/30aOo14

Recebido em: 20.08.2019

Aceito em: 16.09.2019 